\title{
An enriched environment delays the progression from mild cognitive impairment to Alzheimer's disease in senescence-accelerated mouse prone 8 mice
}

\author{
JIAN-ZHONG LI ${ }^{1 *}$, XING-HUA HAO ${ }^{2 *}$, HAI-PING WU ${ }^{1}$, MING LI $^{1}$, XUE-MIN LIU ${ }^{1}$ and ZHI-BING WU ${ }^{1}$ \\ ${ }^{1}$ Department of Human Anatomy, Changzhi Medical College; ${ }^{2}$ Department of Clinical Psychology, \\ Heping Hospital Affiliated to Changzhi Medical College, Changzhi, Shangxi 046000, P.R. China
}

Received July 2, 2020; Accepted October 16, 2020

DOI: $10.3892 / \mathrm{etm} .2021 .10755$

\begin{abstract}
A previous study demonstrated that middle-aged (5-6 months of age) senescence-accelerated mouse prone 8 (SAMP8) mice can be used as animal models of mild cognitive impairment (MCI). An enriched environment (EE) can mitigate cognitive decline and decrease the pathological changes associated with various neurodegenerative diseases. In the present study, the learning-memory abilities of SAMP8 mice during the MCI phase (5 months of age) was evaluated and neuropathological changes in the hippocampus were examined after the mice were exposed to an EE for 60 days. In the Morris water maze test, EE-exposed mice demonstrated significantly decreased escape latency and increased time spent in the target quadrant and number of platform crossings compared with control mice. Terminal deoxynucleotidyl transferase dUTP nick end labeling and Nissl staining showed that EE-exposed mice had reduced neuronal apoptosis and increased number of surviving neurons compared with control mice. Golgi staining, transmission electron microscopy, and immunohistochemical staining demonstrated that EE-exposed
\end{abstract}

Correspondence to: Professor Zhi-Bing Wu, Department of Human Anatomy, Changzhi Medical College, 161 Jiefang East Street, Changzhi, Shangxi 046000, P.R. China

E-mail: czyxywzb2004@sina.com

*Contributed equally

Abbreviations: A $\beta$, amyloid- $\beta$; AD, Alzheimer's disease; AI, apoptotic index; ANOVA: Analysis of variance; APP, amyloid-precursor protein; EE, enriched environment; MCI, mild cognitive impairment; MWM, Morris water maze; Nv, numerical density; OD, optical density; SD, standard deviation; Sv, surface density; SAMP8, senescence-accelerated mouse prone 8; SAMR1, senescence-accelerated mouse resistant 1; SE, standard environment; SYN, synaptophysin; TUNEL, terminal deoxynucleotidyl transferase dUTP nick end labeling

Key words: AD, MCI, apoptosis, neuronal loss, synaptic plasticity, $\mathrm{EE}$ mice exhibited increased dendritic spine densities among secondary and tertiary apical dendrites; increases in synaptic numerical density, synaptic surface density, and expression of synaptophysin; and reduced deposition of amyloid- $\beta(A \beta)$ and expression of amyloid-precursor protein (APP) in the hippocampal CA1 region compared with control mice. These results demonstrate that EE exposure effectively decreases neuronal loss and regulates neuronal synaptic plasticity by reducing the expression of APP and the deposition of A $\beta$ in the hippocampal CA1 region, thereby mitigating cognitive decline in SAMP8 mice during the MCI phase and delaying the progression from MCI to Alzheimer's disease.

\section{Introduction}

Alzheimer's disease (AD) is a chronic neurodegenerative disease characterized by progressive cognitive impairment and impaired learning and memory. AD is the most common form of dementia. As the world's population continues to age and the number of elderly people increases, the number of patients with AD is expected to reach 140 million worldwide by 2050 (1). AD will become one of the most important diseases that affect the health of the elderly population. However, due to the complexity of the pathogenesis of AD and the side effects and tolerability of drugs for its treatment, no effective method or reasonable drug treatment has been developed yet to prevent and treat this disease. Therefore, developing methods to prevent or delay the onset of AD is particularly important.

Mild cognitive impairment (MCI) refers to a condition in which an individual has obvious memory and/or other cognitive defects but is still able to care for him/herself and has not yet reached the diagnostic criteria for dementia, adjusted for age and education level. MCI is currently described as a transitional state between normal aging and AD (2-5). The data showed that the probability of progression to AD in normal elderly individuals was $1-2 \%$, whereas in patients with MCI was as high as $10-15 \%$ (6). Therefore, early diagnosis of MCI can aid the identification of individuals at high risk of dementia, and active, effective interventions in patients with MCI can prevent or delay the development of $\mathrm{AD}$. 
The senescence-accelerated mouse prone 8 (SAMP8) mouse model is considered a suitable, naturally derived animal model of late-onset AD (7-9). A previous study on age-related changes in SAMP8 mice using a grading score, the Morris water maze (MWM) test, Golgi staining, Nissl staining and immunohistochemical staining was conducted (10). The results demonstrated that SAMP8 mice exhibited obvious signs of aging, MCI, and slight neuropathological changes starting at 5 months of age and showed signs similar to those associated with $\mathrm{AD}$ at 7 months old compared with senescence-accelerated mouse resistant 1 (SAMR1) mice. The present study confirmed that SAMP8 mice began to enter the MCI phase at 5 months of age, which suggested that middle-aged SAMP8 mice could be used as a reasonable animal model to examine the transition from MCI to AD (10).

Aging is the result of interactions between genetic and environmental factors. Enriched environment (EE) has been widely used to study brain structural remodeling and functional recovery after an acute brain injury, such as cerebral ischemia, since it was proposed by Hebb in 1947 (11). With advances in research, the effects of EE on neurodegenerative disease rehabilitation have attracted widespread attention. Animal experiments have demonstrated that EE can improve the neurological functions and cognitive performances associated with various neurodegenerative diseases, including AD and Parkinson's disease (12). In addition, it has been reported that lifestyle modifications, including diet, exercise, and cognitive stimulation, may be effective in slowing the progression of MCI to dementia (13). In the present study, the effects of EE exposure on the cognitive functions and neuropathological changes in the hippocampus of SAMP8 mice were evaluated during the MCI phase (5-months old) to determine whether EE exposure can delay the progression from MCI to AD.

\section{Materials and methods}

Animals and groups. A total of 30 male SAMP8 mice in the MCI phase (5-months old) were randomly categorized into either the P8 + EE group ( $n=15)$ or the P8 + standard environment (SE) group $(n=15)$. Mice were housed under EE or SE conditions for 60 days. As a homologous control, 15 male senescence-accelerated mouse resistant 1 (SAMR1) mice aged 5 months (R1 + SE group) were housed under SE conditions for 60 days. All mice were provided by the experimental animal center of The First Hospital Affiliated to Tianjin Medical University. They received a standard rodent diet and water ad libitum and were housed at room temperature $\left(18-22^{\circ} \mathrm{C}\right)$ at a relative humidity of $65-70 \%$. No significant differences in animal body mass were observed among the groups $(\mathrm{P}>0.05)$. All experimental procedures followed the guiding principles of mammalian neuroscience research and were approved by the Ethics Committee for Animal Experiments at the Changzhi Medical College.

Environments. SE: Mice were housed in standard polyethylene squirrel cages $(30 \times 20 \times 15 \mathrm{~cm}$; five mice per cage), with the top covered by stainless-steel wire. The cages only included nesting material.

EE: Mice were housed in large polyethylene squirrel cages (40x25x30 cm; five mice per cage) with the top covered by stainless-steel wire. The cages contained a running wheel, a swing, a slide, a tunnel, and several toys with different colors and shapes, in addition to nesting material. Cages were cleaned and the contents were rearranged once each day at a fixed time, and a 12-h light/dark cycle was implemented (lights on at 7:00 AM).

MWM test. The MWM comprises three components: A circular pool, a platform, and a video capture system (SMART 3.0 Behavioral Video Analysis Software, Panlab). The pool was $120 \mathrm{~cm}$ in diameter and $60 \mathrm{~cm}$ in height and was filled with water $\left(20 \pm 1^{\circ} \mathrm{C}\right)$ made opaque by the addition of carbon ink. The pool was divided into four quadrants. The platform (10 cm in diameter) was placed in the center of quadrant IV (the target quadrant) and was hidden $1 \mathrm{~cm}$ below the water surface. After the mice were housed in the maze laboratory for 2 days, each mouse was placed in the pool near the wall of one quadrant and was allowed to swim freely for $120 \mathrm{sec}$ to adapt to the water temperature and gain familiarity with the task; using this test, mice with existing non-cognitive impairments were identified. The MWM test was conducted daily from 8:00 am to $12: 00 \mathrm{pm}$, and the objects around the pool, including the experimenter, remained in the same location throughout the test.

Positioning navigation test. The mice were gently placed in the water at the midpoint of each quadrant, by turns, facing the pool wall. The video capture system tracked mouse movements and recorded the time required for each mouse to find the platform (escape latency). Each mouse was allowed to swim until it found the platform, for a maximum duration of $120 \mathrm{sec}$, and was allowed to rest on the platform for $20 \mathrm{sec}$. If the mice did not find the platform within $120 \mathrm{sec}$, they were guided to the platform and were maintained on the platform for $20 \mathrm{sec}$. The test was conducted once a day for 4 consecutive days.

Space exploration test. On the fifth day, the platform was removed from the pool to evaluate the memories of the mice regarding the platform location. Keeping all other factors unchanged, the mice were gently placed in the water at the midpoint of quadrant III, facing the pool wall. The video capture system recorded the swimming paths, time spent in the target quadrant, and number of times the platform location was crossed during each 120 -sec test session.

Transmission electron microscopy. From each group, five mice were randomly selected and anesthetized with pentobarbital sodium $(80 \mathrm{mg} / \mathrm{kg})$ by intraperitoneal injection, before opening the thorax to expose the heart. An infusion needle was inserted into the left ventricle while the right atrial appendage was cut. At room temperature, the mice were perfused with $0.9 \%$ normal saline until clear liquid flowed out, and fixed with a $4 \%$ glutaraldehyde solution at the same temperature until the liver became white and the body became stiff. The brain was removed and postfixed for $24 \mathrm{~h}$ in the same fixative. The hippocampal CA1 region was examined and removed under a stereoscopic microscope (magnification, $x 240$ ), referring to the Paxinos mouse brain stereotactic atlas. The CA1 region was fixed with $1 \%$ osmium acid at $4^{\circ} \mathrm{C}$ for $1 \mathrm{~h}$, dehydrated in 
a graded acetone $(50 \%, 15 \mathrm{~min} ; 60 \%, 15 \mathrm{~min} ; 70 \%, 15 \mathrm{~min}$; $80 \%, 15 \mathrm{~min}$; 90\%, $15 \mathrm{~min}$; and 100\%, $15 \mathrm{~min}$; $\mathrm{x} 2$ ) at room temperature, embedded in araldite, and sliced into semi-thin sections (100-nm thick). Superfluous tissues surrounding the hippocampal CA1 region were removed under the microscope based on toluidine blue staining. Consecutive ultrathin (70-nm thick) sections were prepared and stained with uranium acetate and lead citrate, for $30 \mathrm{~min}$ each at $37^{\circ} \mathrm{C}$. Ultrastructures were observed under an H-7500 transmission electron microscope (Hitachi, Ltd.), and three photographs were randomly taken from clear sections (x25,000 magnification). A square-shaped area, defined as a counting frame, was randomly drawn onto each photograph. Synapses were identified according to the synaptic confirmation standard (14) and counted according to the stereological 'forbidden line' method (15). The synaptic numerical density $\left(\mathrm{Nv}\right.$, number/ $\left.\mu \mathrm{m}^{3}\right)$ and surface density $\left(\mathrm{Sv}, \mu \mathrm{m}^{2} / \mu \mathrm{m}^{3}\right)$ were calculated using a stereological method and an image analysis system (16). Nv was calculated according to the formula $\mathrm{Nv}=\mathrm{Na} /(\mathrm{L} / \mathrm{Ko}+\mathrm{T})$; where, $\mathrm{Na}$ is the total number of synapses per square micrometer, $\mathrm{L}$ is the average length of synaptic junction, $\mathrm{T}$ is the thickness of ultrathin section, and Ko is the correction coefficient to correct the overestimation of synaptic junction band length caused by Holmes effect (calculated as follows: $\mathrm{Ko}=1+3 \mathrm{~T} / 2 \mathrm{~L}$ ). Sv was calculated according to the formula $\mathrm{Sv}=2 \mathrm{Ni} / \mathrm{LtKo}$; where, $\mathrm{Ni}$ is the number of crossing points between synaptic junction and test line, Lt is the total length of test line, and Ko is the correction coefficient to correct the overestimation of synaptic junction band length caused by Holmes effect (calculated as aforementioned).

Preparation and staining of tissue sections. The remaining 10 mice in each group were anesthetized with pentobarbital sodium $(80 \mathrm{mg} / \mathrm{kg})$ by intraperitoneal injection, before opening the thorax to expose the heart. An infusion needle was inserted into the left ventricle, and the right atrial appendage was simultaneously cut. At room temperature, the mice were perfused with $0.9 \%$ normal saline until the clear liquid flowed out, followed by a fixative containing $4 \%$ paraformaldehyde in $0.1 \mathrm{M}$ phosphate buffer at a $\mathrm{pH}$ of 7.4 until the liver became white and the body became stiff. The brain was carefully removed and fixed with the same fixative as aforementioned for $24 \mathrm{~h}$. The tissue block between the optic chiasm and the superior colliculus was cut and divided into two halves along the median sagittal plane. The left tissue block was used for Nissl staining, terminal deoxynucleotidyl transferase dUTP nick end labeling (TUNEL) staining, and immunohistochemical staining, whereas the right tissue block was used for Golgi staining. The left tissue block was dehydrated in a graded ethanol series (70\%, 2 h; 80\%, 2 h; $90 \%$, overnight; $95 \%, 90 \mathrm{~min} \times 2$; and $100 \%, 40 \mathrm{~min} \times 2$ ), cleared in xylene (20 min $\mathrm{x} 2)$, and embedded in paraffin; it was then cut serially from the cranial to the caudal side into $5-\mu \mathrm{m}$ sections. Five successive sections were taken at intervals of $50 \mu \mathrm{m}$ and mounted on glass slides coated with polylysine to prepare five sets of sections. One set of sections was used for Nissl staining, another set was used for TUNEL staining, and the remaining three sets were used for immunohistochemical staining of anti-synaptophysin (anti-SYN), anti-A $\beta$, and anti-APP.
Golgi staining. After immersion in mordant solution for 3 days, followed by immersion in $1.5 \% \mathrm{AgNO}_{3}$ solution at room temperature for 5 days in a dark environment, the right tissue block was dehydrated in a graded ethanol series (70\%, 2 h; 80\%, 2 h; 90\%, overnight; 95\%, 90 min x2; and $100 \%, 40 \mathrm{~min} \times 2$ ), cleared in xylene (20 min x2), embedded in paraffin, and cut serially into $60-\mu \mathrm{m}$ sections. For each mouse, 12 randomly chosen neurons fully impregnated, unobscured by neighboring neurons, from 4 sections were analyzed, and the average value was used as the result for this mouse. The lengths (in $\mu \mathrm{m}$ ) of the secondary and tertiary apical dendrites in the hippocampal CA1 region were measured using digitized images under $\mathrm{x} 1,000$ magnification, the number of dendritic spines was independently counted by two different investigators, and the results were cross-checked to preclude systematic analytical errors. In addition, the dendritic spine density was calculated (number/ $\mu \mathrm{m})(17)$.

Nissl staining. A set of sections was conventionally deparaffinized in xylene (10 min $\mathrm{x} 2$ ), dehydrated in a graded ethanol series (100\%, 3 min x2; 95\%, 3 min; 90\%, 3 min; 80\%, 3 min; and $70 \%, 3 \mathrm{~min}$ ), soaked in $1 \%$ cresyl violet at $60^{\circ} \mathrm{C}$ for $30 \mathrm{~min}$, and then washed with distilled water. The sections were differentiated in $95 \%$ ethanol until the Nissl body appeared to be clear, dehydrated rapidly twice in $100 \%$ ethanol, cleared twice in xylene, and coverslipped using a neutral balsam. The numbers of pyramidal cells per field under x400 magnification using light microscope (Olympus Corporation) in the hippocampal CA1 region were counted.

TUNEL staining. Another set of sections was conventionally deparaffinized in xylene (10 min x2), dehydrated in a graded ethanol series (100\%, 3 min x2; 95\%, 3 min; 90\%, 3 min; $80 \%, 3 \mathrm{~min}$ and $70 \%, 3 \mathrm{~min}$ ), and incubated with protease $\mathrm{K}$ for $30 \mathrm{~min}$ at room temperature. After washing with PBS, the sections were incubated with $50 \mu 1$ TUNEL reaction mixture in a wet box at $37^{\circ} \mathrm{C}$ for $60 \mathrm{~min}$. After further washing with PBS, the sections were incubated with $50 \mu \mathrm{l}$ of transformant-peroxidase in a wet box at $37^{\circ} \mathrm{C}$ for $30 \mathrm{~min}$. Finally, the sections were stained using 3,3'-diaminobenzidine, counterstained using hematoxylin, and coverslipped using a neutral balsam [in situ cell apoptosis test kit; Roche Diagnostics (Shanghai) Co., Ltd.]. The number of TUNEL-positive cells and the number of pyramidal cells were counted separately in each field under x400 magnification using a light microscope (Olympus Corporation) in the hippocampal CA1 region. The apoptotic index (AI) was calculated by dividing the number of TUNEL-positive cells by the number of pyramidal cells (18).

Immunohistochemical staining. The remaining three sets of sections were conventionally deparaffinized in xylene (10 min $\mathrm{x} 2)$, dehydrated in a graded ethanol series $(100 \%$, 3 min $x 2$; 95\%, 3 min; 90\%, 3 min; $80 \%, 3$ min; 70\%, 3 min), and immersed in $3 \% \mathrm{H}_{2} \mathrm{O}_{2}$ at room temperature for $20 \mathrm{~min}$ to block the endogenous peroxidase activity. After being subjected to antigen retrieval with citrate buffer solution (OriGene Technologies, Inc.) for $15 \mathrm{~min}$ in a microwave, the sections were incubated with $10 \%$ goat serum (OriGene Technologies, Inc.) in a wet box at room temperature for 
10 min to block nonspecific binding. This was followed by overnight incubation with rabbit anti-SYN polyclonal antibody (1:200; cat. no. ab14692; Abcam), rabbit anti-A $\beta$ polyclonal antibody (1:200; cat. no. bs-0107R; BIOSS), and rabbit anti-APP monoclonal antibody (1:200; cat. no. ab32136; Abcam) at $4^{\circ} \mathrm{C}$. After washing with PBS, the sections were incubated with biotinylated goat anti-rabbit immunoglobulin $\mathrm{G}$ (OriGene Technologies, Inc.) at room temperature for $1 \mathrm{~h}$. The hippocampal CA1 region was imaged under a light microscope (Olympus Coporation; magnification, x400). Image-Pro Plus 6.0 (Media Cybernetics, Inc.) was used to determine the average optical density (OD) for SYN, A $\beta$ and APP in the hippocampal CA1 region.

Data analysis. Repeated measures analysis of variance (ANOVA) was used to analyze the main effects of environment and day (1, 2, 3 and 4 days) on escape latency in the positioning navigation test. One-way ANOVA was used to analyze the effects of environment on the time spent in the target quadrant and the number of platform crossings in the space exploration test. Dendritic spine density, Nv, Sv, number of neurons, and the OD of SYN, A $\beta$, and APP were tested for normality (Kolmogorov-Smirnov test) and equal variance (Levene's test). If both normal distribution and homogeneity of variance were found, comparisons were analyzed using one-way ANOVA, and Cohen's d test was used for pair-wise comparisons. All data are presented as the mean \pm standard deviation. The AI was generated using a Cartesian inspection test. All statistical analyses were performed using SPSS version 25.0 (IBM Corp.). $\mathrm{P}<0.05$ was considered to indicate a statistically significant difference.

\section{Results}

Effects of EE exposure on the cognitive functions of SAMP8 mice during the MCI phase, assessed using the MWM test. During the positioning navigation test, the average escape latencies on training days 1, 2, 3 and 4 in the P8 + EE group were significantly shorter compared with those in the $\mathrm{P} 8+\mathrm{SE}$ group (all $\mathrm{P}<0.01)$ but significantly longer compared with the $\mathrm{R} 1+\mathrm{SE}$ group (all $\mathrm{P}<0.01$ ) (Fig. 1A).

During the space exploration test, the mice in the R1 + SE and P8 + EE groups primarily swam in or near the target quadrant, whereas the mice in the $\mathrm{P} 8+\mathrm{SE}$ group primarily swam along the pool wall and rarely swam near the target quadrant (Fig. 1B). The time spent in the target quadrant was longer in the $\mathrm{P} 8+$ EE group compared with the $\mathrm{P} 8+\mathrm{SE}$ group $(\mathrm{P}<0.01)$ but shorter compared with the $\mathrm{R} 1+\mathrm{SE}$ group $(\mathrm{P}<0.01)$ (Fig. 1C). The number of platform crossings significantly increased in the $\mathrm{P} 8+\mathrm{EE}$ group compared with that in the $\mathrm{P} 8+\mathrm{SE}$ group $(\mathrm{P}<0.01)$ but was fewer than that in the $\mathrm{R} 1+\mathrm{SE}$ group $(\mathrm{P}<0.01)$ (Fig. 1D).

Effects of EE exposure on neuronal loss in the hippocampal $C A 1$ region in SAMP8 mice during the MCI phase. TUNEL staining resulted in the nuclei of apoptotic cells being stained brown (Fig. 2C). As shown in Fig. 2A, the AI of the P8 + EE group was significantly decreased compared with that of the $\mathrm{P} 8+\mathrm{SE}$ group $(\mathrm{P}<0.01)$, but was significantly higher than that of the $\mathrm{R} 1+\mathrm{SE}$ group $(\mathrm{P}<0.01)$.
The Nissl staining results (Fig. 2B and D) showed that the number of neurons in the hippocampal CA1 region was significantly higher in the $\mathrm{P} 8+\mathrm{EE}$ group $(\mathrm{P}<0.01)$ compared with that in the P8 + SE group but remained significantly lower than that in the $\mathrm{R} 1+\mathrm{SE}$ group $(\mathrm{P}<0.01)$.

Effects of EE exposure on synaptic plasticity in the hippocampal CA1 region of SAMP8 mice during the $M C I$ phase. Golgi staining was used to observe secondary and tertiary apical dendrites in the hippocampal CA1 region (Fig. 3E). The lengths of secondary and tertiary apical dendrites were measured, the numbers of dendritic spines were counted, and dendritic spine densities were determined. As shown in Fig. 3A, the dendritic spine density of the P8 + EE group was significantly increased compared with that of the $\mathrm{P} 8+\mathrm{SE}$ group $(\mathrm{P}<0.01)$ but was significantly lower than that of the $\mathrm{R} 1+\mathrm{SE}$ group $(\mathrm{P}<0.01)$.

Transmission electron microscopy was used to observe the ultrastructure of excitatory synapses in the hippocampal CA1 region (Fig. 3F). The Nv and $\mathrm{Sv}$ were calculated using a stereological method and an image analysis system. The results showed significant differences in the $\mathrm{Nv}$ and $\mathrm{Sv}$ of synapses in the hippocampal CA1 region between the P8 + EE and $\mathrm{P} 8+\mathrm{SE}$ groups (all $\mathrm{P}<0.01$ ), and the $\mathrm{Nv}$ and $\mathrm{Sv}$ of synapses in the hippocampal CA1 region in the P8 + EE group were significantly lower than those in the $\mathrm{R} 1+\mathrm{SE}$ group (all $\mathrm{P}<0.01)$ (Fig. 3B and C).

The immunohistochemical staining of SYN showed that immune reaction products, observed as a brownish-yellow color, were distributed throughout the neuropil of pyramidal cells but not in the nucleus and cytoplasm (Fig. 3G). The OD of the immune reaction products in each group was measured and found that the expression of immune reaction products in the P8 + EE group was significantly increased compared with that in the $\mathrm{P} 8+\mathrm{SE}$ group $(\mathrm{P}<0.01)$, but was significantly lower than that in the $\mathrm{R} 1+\mathrm{SE}$ group $(\mathrm{P}<0.01)$ (Fig. 3D).

Effects of EE exposure on the deposition of $A \beta$ and the expression of APP in the hippocampal CA1 region of SAMP8 mice during the MCI phase. Immunohistochemical staining for $A \beta$ showed that $A \beta$-immunoreactive granules, which appeared as a dark yellow color, were primarily distributed in the cytoplasm and protuberances (Fig. 4C). A $\beta$ was deposited in large amounts in the $\mathrm{P} 8+\mathrm{SE}$ group, resembling senile plaques (Fig. 4C). The A $\beta$-immunoreactive granules in the hippocampal CA1 region in the P8 + EE group were observed at significantly reduced numbers and densities compared with those in the P8 + SE group (Fig. 4C). In contrast, the deposition of $\mathrm{A} \beta$ was rarely observed in the $\mathrm{R} 1+\mathrm{SE}$ group (Fig. 4C). The $\mathrm{OD}$ of $\mathrm{A} \beta$ in the $\mathrm{P} 8+\mathrm{EE}$ group was significantly decreased compared with that in the $\mathrm{P} 8+\mathrm{SE}$ group $(\mathrm{P}<0.01)$ but remained significantly higher than that in the $\mathrm{R} 1+\mathrm{SE}$ group $(\mathrm{P}<0.01)$ (Fig. 4A).

The immunohistochemical staining of APP revealed that immune reaction products, observed in brown color, were distributed in the cytoplasm and the axons of neurons (Fig. 4D). The measurement of the OD of the immune reaction products in each group showed that the expression of immune reaction products in the $\mathrm{P} 8+\mathrm{EE}$ group was significantly decreased compared with the $\mathrm{P} 8+\mathrm{SE}$ group $(\mathrm{P}<0.01)$ but was 


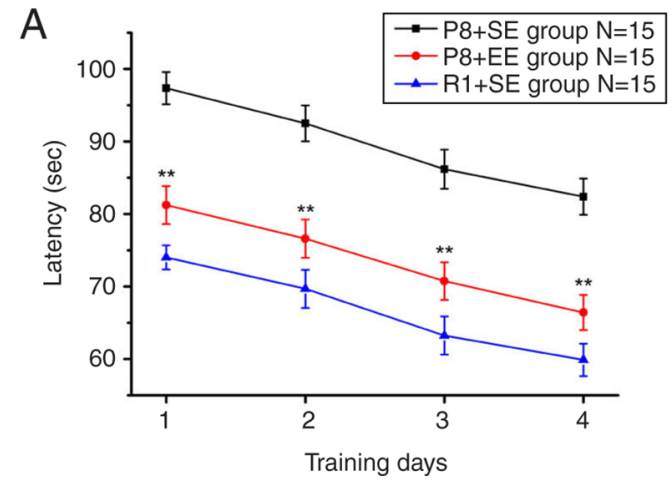

B
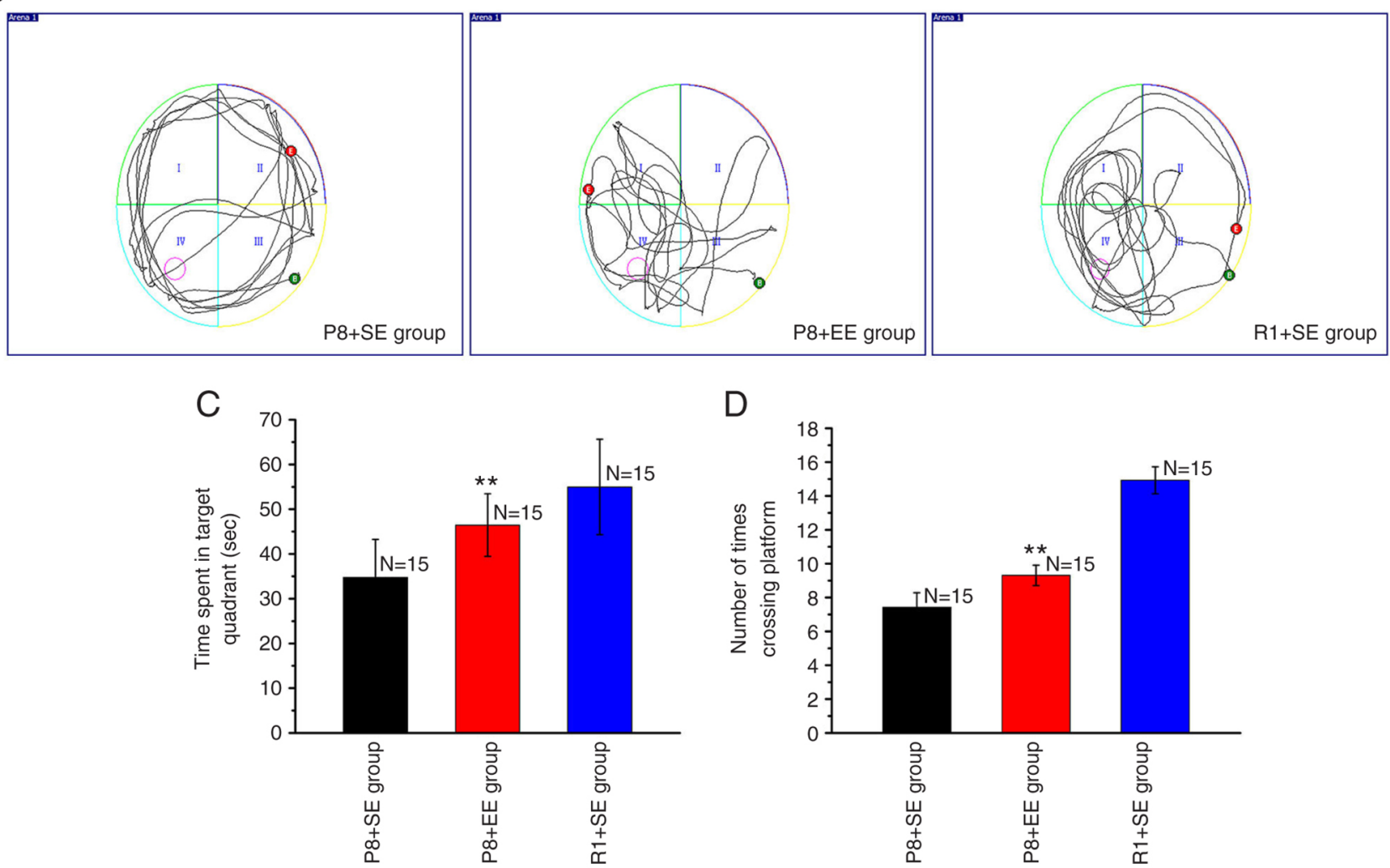

Figure 1. Effects of different environments on the spatial learning and memory abilities of mice assessed using the Morris water maze test. Data are presented as latencies to identify the hidden platform over 4 consecutive training days (A) in the positioning navigation test, whereas the time spent in the target quadrant (C) and the number of platform crossings (D) were assessed to evaluate memory in the space exploration test. Photographs indicate the swimming paths (B) in the space exploration test. Each point or column represents the mean $\pm \mathrm{SD}$. ${ }^{* *} \mathrm{P}<0.01$ vs. the P8 $+\mathrm{SE}$ and $\mathrm{R} 1+\mathrm{SE}$ groups. $\mathrm{SE}$, standard environment; EE, enhanced environment.

significantly higher than that in the $\mathrm{R} 1+\mathrm{SE}$ group $(\mathrm{P}<0.01)$ (Fig. 4B).

\section{Discussion}

In humans, the aging process is accompanied by a decline in cognitive function, which is often associated with progressive declines in the functions of multiple systems, including the visual, auditory, olfactory, masticatory and motor systems. An active lifestyle that includes mental and social aspects could improve the functions of these systems; this has been shown to have positive effects on the brain regions that mediate cognitive function, thereby mitigating declines in cognitive ability $(19,20)$. The concept of EE was first introduced by the American scholar Hebb in 1947 (11). For more than 70 years, EE has been demonstrated to be beneficial for the brain, particularly the hippocampus, at the molecular, cellular and behavioral levels. At the behavioral level, EE not only improves spatial, non-spatial and long-term memory in normal animals (21-23) but also ameliorate human-like neurological symptoms in animal models of human neurological pathology, including the cognitive decline associated with AD (24-28). Currently, accumulated evidence has demonstrated that EE exposure can mitigate cognitive decline in young SAMP8 mice (29-31). Griñán-Ferré et al $(29,30)$ raised SAMP8 mice under EE conditions from 21 days after birth until 3 months of age and found a better generalized performance in SAMP8 mice raised under EE conditions compared with those raised under SE conditions, assessed by behavioral and learning tests. Yuan et al (31) housed 3-month-old female SAMP8 mice under EE conditions for 3 months, and the results demonstrated that EE exposure improved cognitive 
A

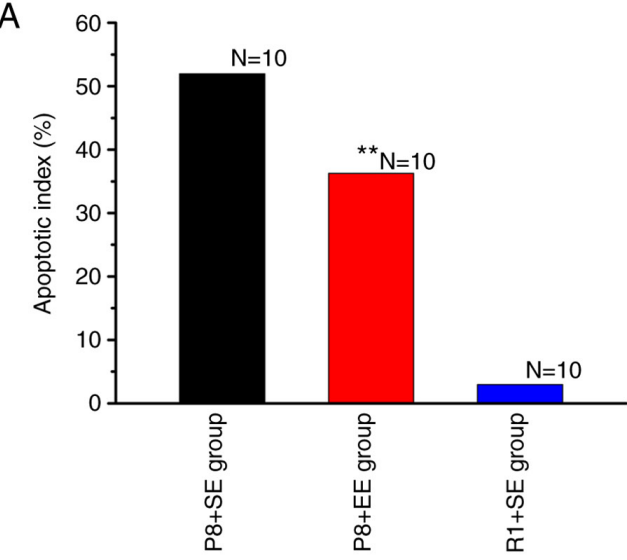

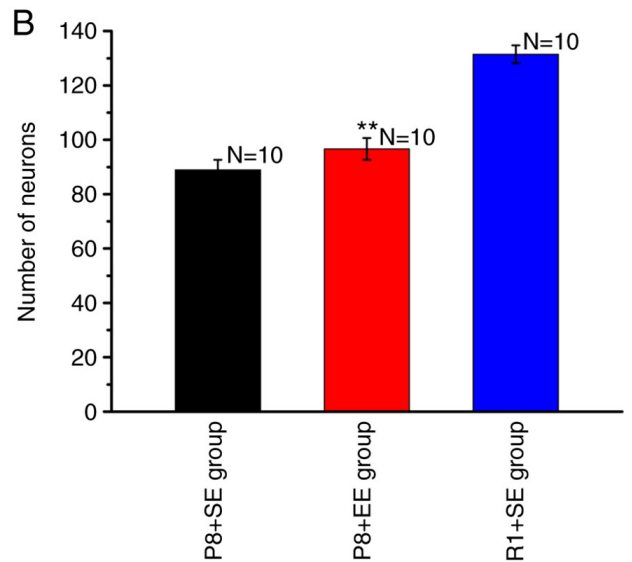
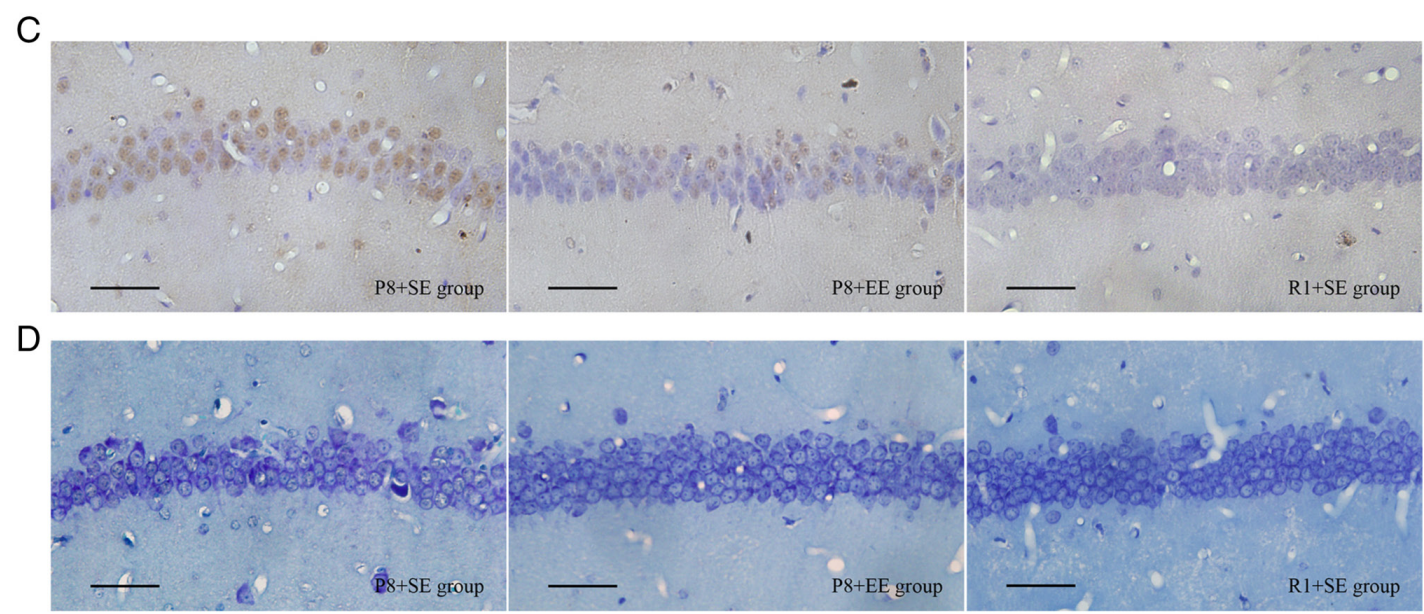

Figure 2. Effects of different environments on neuronal loss in the hippocampal CA1 region of mice. EE exposure resulted in (A) a significant decrease in the AI value and (B) a significant increase in the number of neurons. Photomicrographs show TUNEL staining (C) and Nissl staining (D) Scale bar, $100 \mu \mathrm{m}$ $\left(\mathrm{C}\right.$ and D) ${ }^{* *} \mathrm{P}<0.01$ vs. P8 + SE and R1 + SE groups. EE, enriched environment; AI, apoptotic index; SE, standard environment; OD, optical density.

performance, assessed by the MWM test and a step-down avoidance experiment. In the present study, compared with mice under SE conditions, mice under EE conditions were housed in large, polyethylene squirrel cages, that provided opportunities to perform more activities, including a running wheel, a swing and a slide, increasing the opportunities for voluntary exercise and likely increased aerobic exercise. In addition, mice housed under the EE conditions had access to a tunnel and several toys with different colors and shapes. Additionally, the cages were cleaned and positions of the objects rearranged once a day at a fixed time to enhance visual stimulation. After 2 months, the learning and memory abilities of middle-aged SAMP8 and SAMR1 mice housed under different environments were evaluated using the MWM test. The results showed that mice in the P8 + EE group exhibited shorter escape latencies compared with mice in the $\mathrm{P} 8+\mathrm{SE}$ group during the positioning navigation test. $\mathrm{P} 8+\mathrm{EE}$ mice also spent more time in the target quadrant compared with mice in the P8 $+\mathrm{SE}$ group during the space exploration test. Moreover, the number of platform crossings increased significantly for the P8 + EE group compared with that for the P8 + SE group. However, a significant difference was observed between mice in the P8 $+\mathrm{EE}$ and $\mathrm{R} 1+\mathrm{SE}$ groups for escape latencies, time spent in the target quadrant, and the number of platform crossings. These behavioral results indicated that EE exposure could be used as a rehabilitation strategy to mitigate the cognitive impairments of SAMP8 mice during the MCI phase and to delay the progression from MCI to AD.

The hippocampus is an important structure in limbic system, which is associated with learning, memory and cognition. The hippocampal CA1 region is an important part of learning and memory, information processing and signal transmission. It is responsible for spatial learning and memory $(32,33)$. The selective vulnerability of distinct regions of the brain is a critical factor in neurodegenerative disorders. In Alzheimer's disease (AD), neurons in hippocampus situated in medial temporal lobe are immensely damaged (34). Neurons in the hippocampal CA1 region are the most sensitive of the entire forebrain, and are considered as the most vulnerable neurons of the hippocampus $(35,36)$. It is the most sensitive area to hypoxia and other damage, also known as vulnerable area (35). In the present study, neuropathological changes in the hippocampal CA1 region were examined after the mice were exposed to different environments for 60 days.

Compared with the number of neurons in the hippocampus of age-matched normal elderly people, the hippocampus of patients with AD is significantly reduced (37). Autopsies of patients with $\mathrm{AD}$ and experiments performed in animal models of AD have revealed higher numbers of apoptotic cells in the hippocampus (38), which suggests that abnormal apoptosis is responsible for neuronal losses in the hippocampus of patients 
A

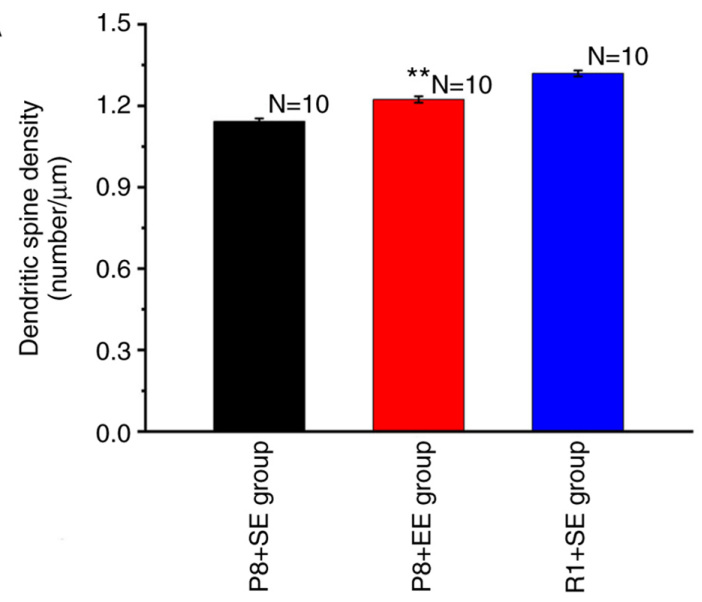

C

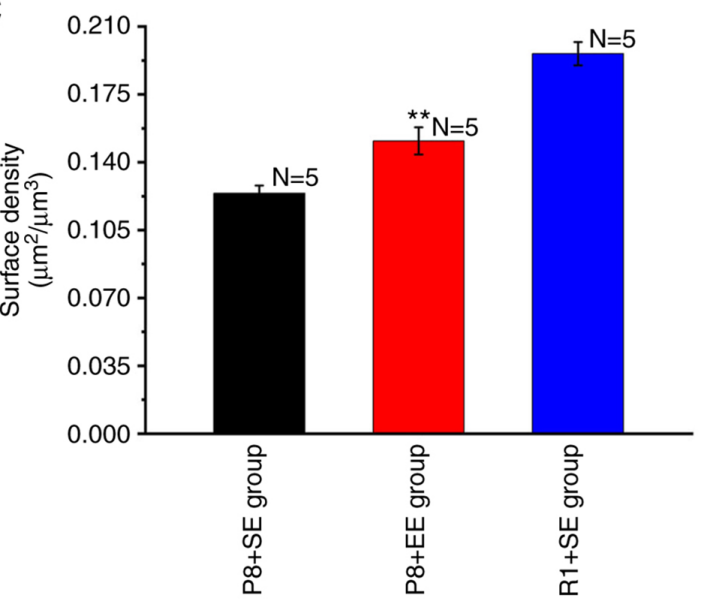

B

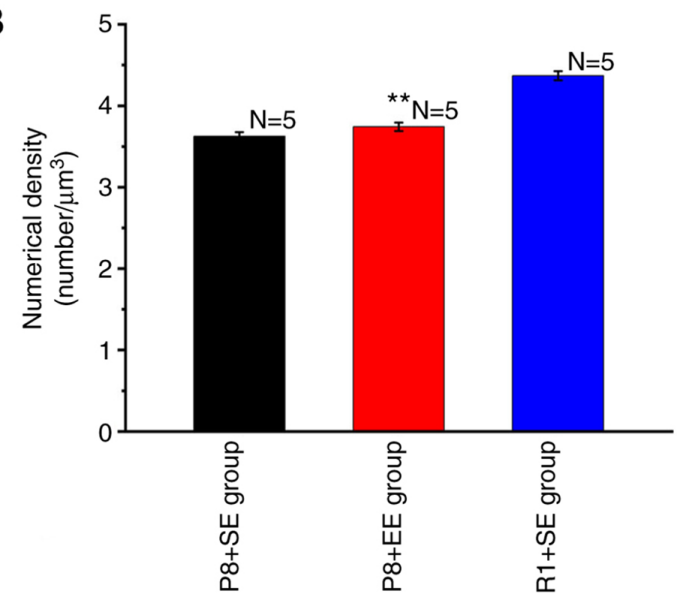

D

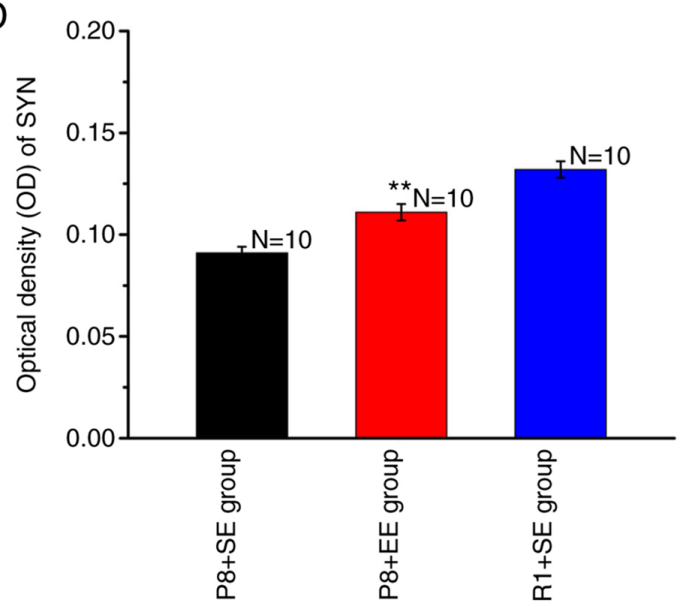

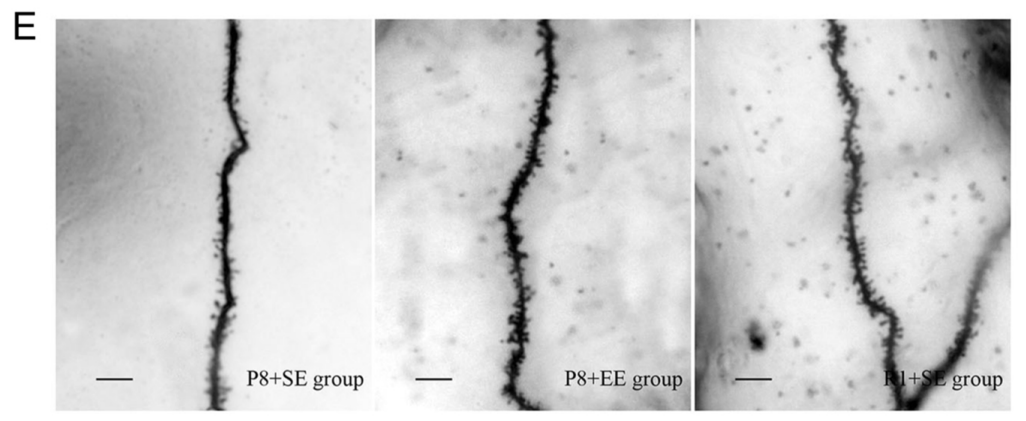

$\mathrm{F}$

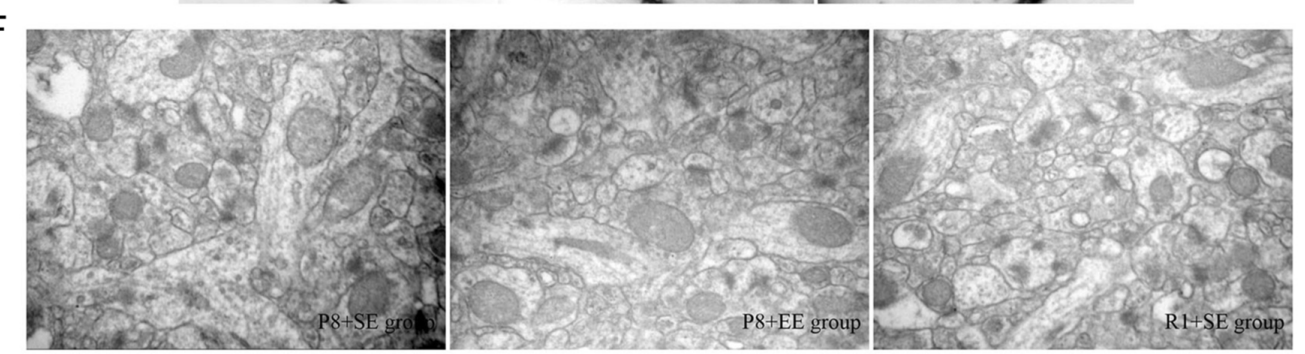

G

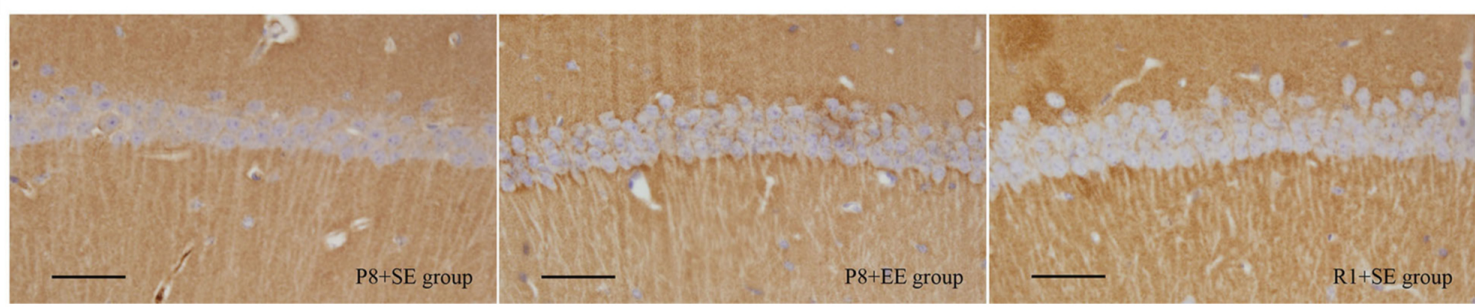

Figure 3. Effects of different environments on synaptic plasticity in the hippocampal CA1 region of mice. EE exposure increased the dendritic spine density (A) Nv (B) Sv (C) and expression of SYN (D) in the hippocampal CA1 region. Photomicrographs show representative images of Golgi staining (E) transmission electron microscopy (F) and immunohistochemical staining (G) Scale bars, $50 \mu \mathrm{m}(\mathrm{E})$ and $100 \mu \mathrm{m}(\mathrm{G})$ Each column represents the mean \pm SD. ${ }^{* *} \mathrm{P}<0.01$ compared with the P8 + SE and R1 + SE groups. EE, enriched environment; SE, standard environment; Nv, synaptic numerical density; SV, surface density; SYN, synaptophysin. 
A

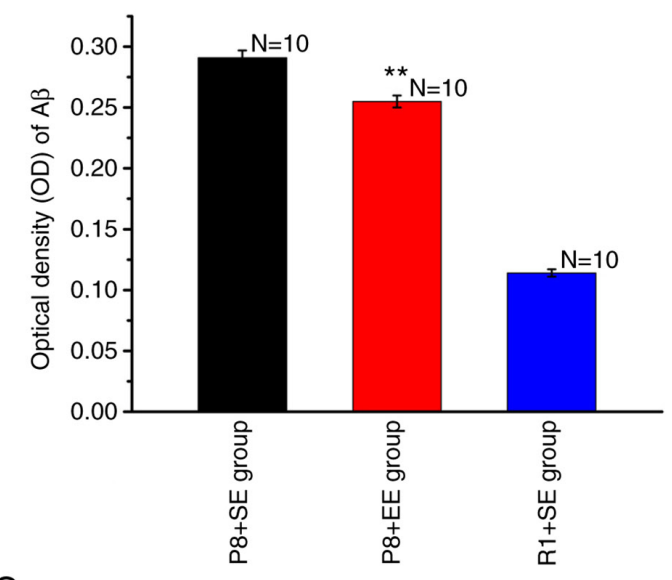

B

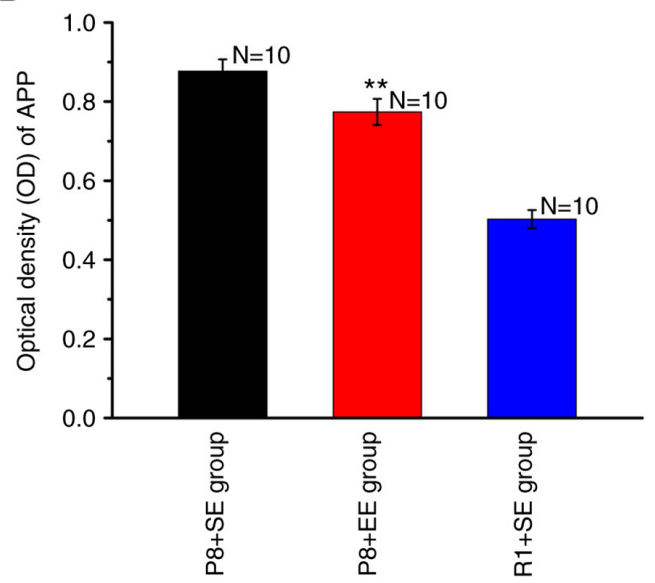

C
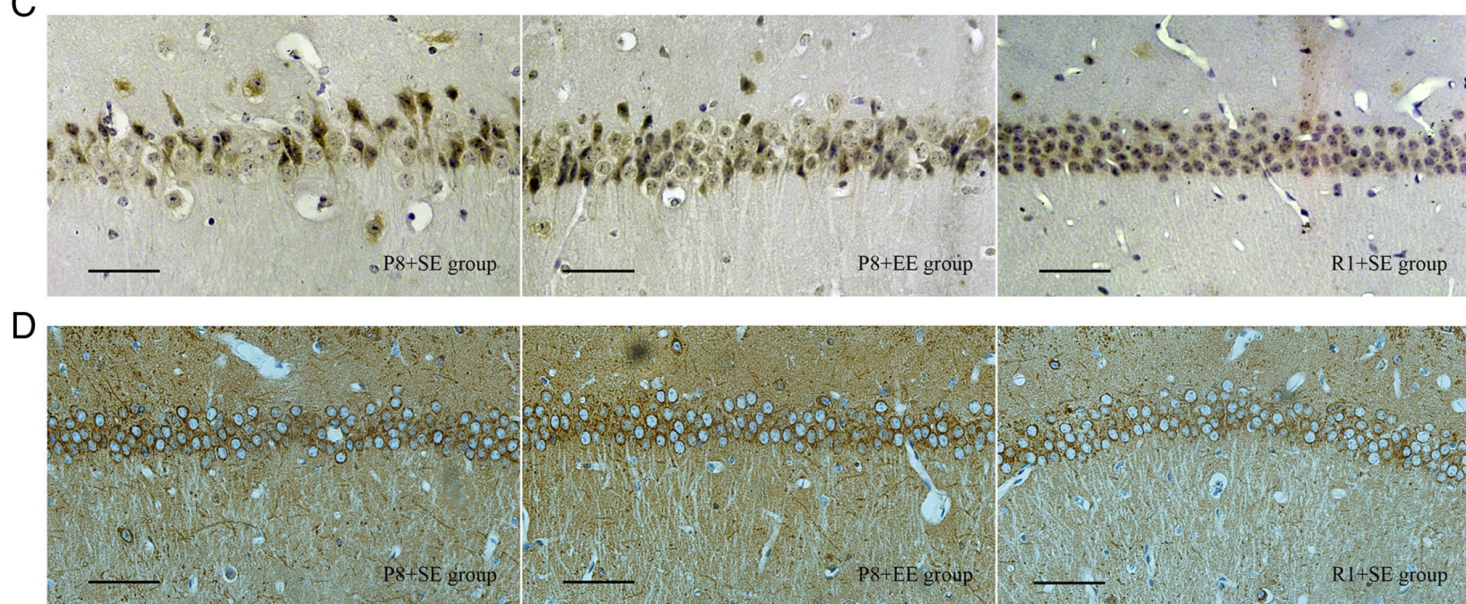

Figure 4. Effects of different environments on the deposition of A $\beta$ and the expression of APP in the hippocampal CA1 region of mice. EE exposure resulted in a significant decline in the deposition of $\mathrm{A} \beta(\mathrm{A})$ and the expression of APP (B) Photomicrographs show the immunohistochemical staining of $\mathrm{A} \beta(\mathrm{C})$ and APP (D) Scale bar, $100 \mu \mathrm{m}$ (C and D) Each column represents the mean $\pm \mathrm{SD}$. ${ }^{* *} \mathrm{P}<0.01$ vs. the P8 $+\mathrm{SE}$ and R1 + SE groups. EE, enriched environment; SE, standard environment; APP, amyloid-precursor protein; A $\beta$, amyloid- $\beta$; OD, optical density.

with AD. Studies have shown that EE exposure may reduce abnormal cell apoptosis $(39,40)$ and cause changes in the morphology and structure of the brain at both macro and micro levels, such as increasing the thickness of the cerebral cortex, area of the cerebral sulcus, and number of neurons $(41,42)$. Griñan-Ferré et al demonstrated that EE exposure decreased the levels of Bax and antiapoptotic Bcl-2 proteins and reduced caspase-3 activity, thereby preventing neuronal apoptosis and loss in SAMP8 mice (29). In agreement with these results, we found that in the hippocampal CA1 region, apoptotic neurons were reduced significantly, as assessed by TUNEL staining, and existing neurons were significantly increased, as assessed by Nissl staining, in the P8 + EE group compared with the P8 + SE group. However, these indicators, including AI and the number of existing neurons, also differed significantly between the P8 + EE and R1 + SE groups. Mitochondria play a pivotal role in the process of integrating all types of death signal stimulation and determining cell fate. By releasing cytochrome $\mathrm{c}$ and other related apoptotic factors, mitochondria can initiate caspase protein cascade reaction and induce cell apoptosis; it can also produce a large number of free radicals and destroy the electron transmission of respiratory chain to cause ATP synthesis disorder and induce cell necrotic death (43). Combined with these findings, it is speculated that
EE condition may decrease apoptosis by affecting mitochondrial function, including caspase activity and ATP production; this hypothesis was be verified through relevant experiments in the present study.

The synaptic plasticity is the neurobiological basis for learning and memory activities $(44,45)$. Synapses, which are the basic unit of transmission of information in the central nervous system, form connections and transmit electrical and chemical signals between neurons (46). Structural and functional damage to synapses has been identified as one of the pathological bases of learning and memory impairment in patients with AD $(47,48)$. Dendritic spines, which are protrusions that extend outward from the neuronal dendrite, form the structural bases of neuronal connections in the brain and are the primary sites of synapse formation (49). Dendritic spines accept and transfer information, and their upregulation can increase communication and transmission $(50,51)$. During learning and memory processes, changes in synaptic structural plasticity are frequently accompanied by changes in dendritic spines, including formation, expansion, atrophy and abscission. Accumulating studies have identified changes in the morphology and quantity of dendritic spines associated with neurodegenerative diseases such as AD $(52,53)$. Several studies have demonstrated that the dendritic spine density of 
the secondary and tertiary dendrites in hippocampal neurons is significantly lower in SAMP8 mice compared with SAMR1 mice $(10,17)$. EE exposure can modulate the shape, number and function of dendritic spines $(54,55)$ and considerably increase dendritic spine densities of neocortical, hippocampal and cerebellar neurons (56-58). In the present study, it was found that the dendritic spine density in SAMP8 mice raised under EE conditions was significantly increased compared with that in SAMP8 mice raised under SE conditions, but was significantly lower compared with that in SAMR1 mice raised under SE conditions. To further elucidate the effects of EE exposure on the synapses in SAMP8 mice, the ultrastructure of the hippocampal CA1 region was examined using transmission electron microscopy and calculated synaptic count indices, including $\mathrm{Nv}$ and $\mathrm{Sv}$, using a stereological method and an image analysis system. The results showed that EE exposure increased the density of synaptic contacts on the dendritic spines of hippocampal CA1 neurons. However, significant differences in $\mathrm{Nv}$ and $\mathrm{Sv}$ were observed between the P8 $+\mathrm{EE}$ and R1 + SE groups.

SYN is a glycoprotein that is located on the membranes of presynaptic vesicles, and SYN expression can accurately and objectively reflect the distribution and density of synapses (59), since SYN is closely associated with synapse formation and reconstruction (60). The degree of cognitive decline in animal models of AD has been correlated with changes in SYN expression in the hippocampus $(17,61-64)$. The present study demonstrated that EE exposure increased the expression of SYN in the hippocampal CA1 region, which further indicates that EE exposure was able to increase neuronal synapses and improve synaptic plasticity in SAMP8 mice. Collectively, these results suggest that the observed declines in learning and memory abilities in SAMP8 mice are closely associated with synaptic plasticity in the hippocampal CA1 region and that EE exposure effectively regulates synaptic plasticity and reduces synaptic loss.

The deposition of $A \beta$ is a common pathological change identified in brain regions associated with neurodegenerative diseases such as AD and MCI (65), and the present results showed that the average $A \beta$ absorbance in the P8 + SE group significantly increased compared with that in the R1 + SE group. Accumulating research has demonstrated that EE exposure may decrease the $A \beta$ content in the hippocampus. Male APPswe X PS1E9 mice were exposed to an EE for 5 months, starting at the age of 1 month, and the results of biochemical and histological analyses showed decreases in both the steady-state levels of $A \beta$ peptides and $\mathrm{A} \beta$ deposition in the brains of mice exposed to EE compared with mice exposed to SE (66). Four months of continuous EE stimulation in 30-day-old female TgCRND8 mice resulted in significant reductions in $\mathrm{A} \beta$ plaques in the neocortex and hippocampus (67). Berardi et al (68) found that AD11 mice exposed to EE from 2 to 7 months of age exhibited marked reductions in the presence of $\mathrm{A} \beta$ clusters in the hippocampus. Ziegler-Waldkirch et al (69) exposed pregnant 5xFAD mice to EE for 18 days and found that hippocampal and cortical $A \beta$ plaque pathology was significantly decreased compared with that in pregnant mice housed under SE conditions, reaching an $\mathrm{A} \beta$-plaque load similar to that in the non-pregnant control group, which was housed under SE conditions. A review examining the neuroprotective effects of physical activity on the brain in patients with AD concluded that physical activity may improve cognitive dysfunction by reducing $A \beta$ deposition in the brain (70). In the present study, it was also found that EE exposure significantly decreased the deposition of $\mathrm{A} \beta$ in the hippocampal CA1 region in SAMP8 mice. $\mathrm{A} \beta$ is a product of APP that is formed under the action of $\beta$-secretase or $\gamma$-secretase. Previous studies have shown that EE exposure significantly decreases APP levels in the hippocampus $(29,71)$. In addition, the present study demonstrated that EE exposure significantly decreased the expression of APP in the hippocampal CA1 region in SAMP8 mice, indicating that EE exposure can decrease the production and deposition of $A \beta$, which is likely mediated by decreasing APP expression. A $\beta$ is a neurotoxic peptide that can promote neuronal loss and mediate synaptic loss and dysfunction in specific regions by disrupting the mitochondrial membrane potential, decreasing ATP generation, enhancing intracellular reactive oxygen species production and activating apoptosis factors and mitophagy (46,72-79).

Based on the aforementioned findings, it is speculated that EE exposure may effectively decrease neuronal loss and regulate neuronal synaptic plasticity by reducing the expression of APP and the deposition of A $\beta$ in the hippocampal CA1 region, so as to mitigate cognitive decline in SAMP8 mice during the MCI phase and delay the progression from MCI to AD. EE alone can play a role in ameliorating human-like neurological symptoms observed in animal models of human neurological pathology. Remarkably, the combination of drugs and EE effectively reduces drug-associated side effects and can promote the therapeutic effects of the drugs $(71,76,80)$. Therefore, as a low-cost, low-risk and very effective method, EE exposure should attract widespread attention for the rehabilitation of neurodegenerative diseases.

\section{Acknowledgements}

Not applicable.

\section{Funding}

This study was supported by the Scientific Research Program of Health Commission in Shanxi of China (grant no. 2015158; to JZL) and the Scientific and Technological Innovation Programs of Higher Education Institutions in Shanxi of China (grant no. 2019L0676 to JZL). Funders had no involvement in the study design; data collection, analysis and interpretation, manuscript writing or decision to submit the paper for publication.

\section{Availability of data and materials}

All data generated or analyzed during this study are included in this published article.

\section{Authors' contributions}

Study design: JZL and XHH. Experiment implementation: JZL, HPW and ML. Data analysis: XML and ZBW. Manuscript 
writing: JZL and XHH. All authors read and approved the final manuscript.

\section{Ethics approval and consent to participate}

All experimental procedures followed the guiding principles of mammalian neuroscience research and were approved by the Ethics Committee for Animal Experiments at Changzhi Medical College (approval no. DW2015018).

\section{Patient consent for publication}

Not applicable.

\section{Competing interests}

The authors declare that they have no competing interests.

\section{References}

1. Ribarič S: The rationale for insulin therapy in Alzheimer's disease. Molecules 21: 689, 2016.

2. Petersen RC, Smith GE, Waring SC, Ivnik RJ, Tangalos EG and Kokmen E: Mildcognitive impairment: Clinical characterization and outcome. Arch Neurol 56: 303-308, 1999.

3. Winblad B, Palmer K, Kivipelto M, Jelic V, Fratiglioni L, Wahlund LO, Nordberg A, Bäckman L, Albert M, Almkvist $\mathrm{O}$, et al: Mild cognitive impairment-beyond controversies, towards a consensus: Report ofthe international working group on mild cognitive impairment. J Intern Med 256: 240-246, 2004.

4. Albert MS, DeKosky ST, Dickson D, Dubois B, Feldman HH, Fox NC, Gamst A, Holtzman DM, Jagust WJ, Petersen RC, et al The diagnosis of mild cognitive impairment due to Alzheimer's disease: Recommendations from the national institute on aging-Alzheimer's association workgroups on diagnostic guidelines for Alzheimer's disease. Alzheimers Dement 7: 270-279, 2011.

5. Yi D, Choe YM, Byun MS, Sohn BK, Seo EH, Han J, Park J, Woo JI and Lee DY: Differences in functional brain connectivity alterations associated with cerebral amyloid deposition in amnestic mild cognitive impairment. Front Aging Neurosci 7: 15, 2015.

6. Min BQ, Zhang LN, Lu Y, Zhou AH, Wei CB and Jian JP: Degeneration of optic nerve and retina in patients of mild cognitive impairment and Alzheimer's disease. J Neurosci Ment Heal 12: 491-494, 2012.

7. Cheng XR, Zhou WX and Zhang YX: The behavioral, pathological and therapeutic features of the senescence-accelerated mouse prone 8 strain as an Alzheimer's disease animal model. Ageing Res Rev 13: 13-37, 2014.

8. Wang JH, Ye FQ, Cheng XR, Zhang XR, Liu F, Liu G, Ni M, Qiao SY, Zhou WX and Zhang YX: The effects of LW-AFC on intestinal microbiome in senescence-accelerated mouse prone 8 strain, a mouse model of Alzheimer's disease. J Alzheimers Dis 53: 907-919, 2016.

9. Griñán-Ferré C, Corpas R, Puigoriol-Illamola D, Palomera-Ávalos V, Sanfeliu C and Pallàs M: Understanding epigenetics in the neurodegeneration of Alzheimer's disease: SAMP8 mouse model. J Alzheimers Dis 62: 943-963, 2018.

10. Kang L, Li S, Xing ZG, Li JZ, Su YH, Fan P, Wang L and Cui HX: Dihydrotestosterone treatment delays the conversion from mild cognitive impairment to Alzheimer's disease in SAMP8 mice. Horm Behav 65: 505-515, 2014.

11. Hebb DO: The effects of early experience on problem-solving at maturity. Am Psychol 2: 306-307, 1947.

12. Meng FT, Zhao J, Ni RJ, Fang H, Zhang LF, Zhang Z and Liu YJ: Beneficial effects of enriched environment on behaviors were correlated with decreased estrogen and increased BDNF in the hippocampus of male mice. Neuro Endocrinol Lett 36: 490-497, 2015.

13. Sanford AM: Mild cognitive impairment. Clin Geriatr Med 33: 325-337, 2017.
14. He YS, Yao ZB, Gu YM, Kuang GB and Chen YC: Nerve growth factor promotes collateral sprouting of cholinergic filbers in the septohippocampal cholinergic system of aged rats with fimbria transaction. Brain Res 586: 27-35, 1992.

15. Jones DG and Calverley RK: Frequency of occurrence of perforated synapses in developing rat neocortex. Neurosci Lett 129: 189-192, 1991.

16. He JF, Qian G, Ling X, Wu MS, Guo P and Luo SY: Compound ruikangxin can reverse the structural plasticity of synapses in hippocampus, amygdala and nucleus accumbens in morphine withdrawal rats. Acta Anatomica Sin 42: 300-306, 2011 (In Chinese).

17. Li S, Kang L, Zhang C, Xie GS, Li N, Zhang Y, Du J and Cui HX: Effects of dihydrotestosterone on synaptic plasticity of hippocampus in male SAMP8 mice. Exp Gerontol 48: 778-785, 2013.

18. Guo LZ, Li LM and Zhang C: Effects of S14G-humanin on A331-35-induced dysfunction of learning and memory and neuronal apoptosis in rat. Chin J Neuroanatomy 27: 164-168, 2011 (In Chinese).

19. Haesner M, O'Sullivan JL, Gövercin M and SteinhagenThiessen E: Requirements of older adults for a daily use of an internet-based cognitive training platform. Inform Health Soc Care 40: 139-153, 2015.

20. Leon M and Woo C: Environmental enrichment and successful aging. Front Behav Neurosci 12: 155, 2018.

21. Bruel-Jungerman E, Laroche S and Rampon C: New neurons in the dentate gyrus are involved in the expression of enhanced long-term memory following environmental enrichment. Eur J Neurosci 21: 513-521, 2005.

22. Leggio MG, Mandolesi L, Federico F, Spirito F, Ricci B, Gelfo F and Petrosini L: Environmental enrichment promotes improved spatial abilities and enhanced dendritic growth in the rat. Behav Brain Res 163: 78-90, 2005.

23. Rampon C, Tang YP, Goodhouse J, Shimizu E, Kyin M and Tsien JZ: Enrichment induces structural changes and recovery from nonspatial memory deficits in CA1 NMDAR1-knockout mice. Nat Neurosci 3: 238-244, 2000.

24. Arranz L, De Castro NM, Baeza I, Giménez-Llort L and De la Fuente M: Effect of environmental enrichment on the immunoendocrine aging of male and female triple-transgenic 3xTg-AD mice for Alzheimer's disease. J Alzheimers Dis 25: 727-737, 2011.

25. Polito L, Chierchia A, Tunesi M, Bouybayoune I, Kehoe PG, Albani D and Forloni G: Environmental enrichment lessens cognitive decline in APP23 mice without affecting brain sirtuin expression. J Alzheimers Dis 42: 851-864, 2014.

26. Stuart KE, King AE, Fernandez-Martos CM, Dittmann J, Summers MJ and Vickers JC: Mid-life environmental enrichment increases synaptic density in CA1 in a mouse model of $\mathrm{A} \beta$-associated pathology and positively influences synaptic and cognitive health in healthy ageing. J Comp Neurol 525: 1797-1810, 2017.

27. Griñán-Ferré C, Izquierdo V, Otero E, Puigoriol-Illamola D, Corpas R, Sanfeliu C, Ortuño-Sahagún D and Pallàs M: Environmental enrichment improves cognitive deficits, AD hallmarks and epigenetic alterations presented in 5xFAD mouse model. Front Cell Neurosci 12: 224, 2018.

28. Stuart KE, King AE, King NE, Collins JM, Vickers JC and Ziebell JM: Late-life environmental enrichment preserves short-term memory and may attenuate microglia in male APP/PS1 mice. Neuroscience 408: 282-292, 2019.

29. Griñan-Ferré C, Pérez-Cáceres D, Gutiérrez-Zetina SM, Camins A, Palomera-Avalos V, Ortuño-Sahagún D, Rodrigo MT and Pallàs M: Environmental enrichment improves behavior, cognition, and brain functional markers in young senescence-accelerated prone mice (SAMP8). Mol Neurobiol 53: 2435-2450, 2016.

30. Griñan-Ferré C, Puigoriol-Illamola D, Palomera-Ávalos V, Pérez-Cáceres D, Companys-Alemany J, Camins A, Ortuño-Sahagún D, Rodrigo MT and Pallàs M: Environmental enrichment modified epigenetic mechanisms in SAMP8 mouse hippocampus by reducing oxidative stress and inflammaging and achieving neuroprotection. Front Aging Neurosci 8: 241, 2016.

31. Yuan ZY, Wang MW, Yan BY, Gu P, Jiang XM, Yang XF and Cui DS: An enriched environment improves cognitive performance in mice from the senescence-accelerated prone mouse 8 strain: Role of upregulated neurotrophic factor expression in the hippocampus. Neural Regen Res 7: 1797-1804, 2012.

32. Khan UA, Liu L, Provenzano FA, Berman DE, Profaci CP, Sloan R, Mayeux R, Duff KE and Small SA: Molecular drivers and cortical spread of lateral entorhinal cortex dysfunction in preclinical Alzheimer's disease. Nat Neurosci 17: 304-311, 2014. 
33. Witter MP: Organization of the entorhinal-hippocampal system: A review of current anatomical data. Hippocampus 3: 33-44, 1993.

34. Dharshini SAP, Taguchi YH and Gromiha MM: Exploring the selective vulnerability in Alzheimer disease using tissue specific variant analysis. Genomics 111: 936-949, 2019.

35. Schmidt-Kastner R and Freund TF: Selective vulnerability of the hippocampus in brain ischemia. Neuroscience 40: 599-636, 1991.

36. Morrison JH and Hof PR: Selective vulnerability of corticocortical and hippocampal circuits in aging and Alzheimer's disease. Prog Brain Res 136: 467-486, 2002.

37. Zilkova M, Koson $\mathrm{P}$ and Zilka N: The hunt for dying neurons: Insight into the neuronal loss in Alzheimer's disease. Bratisl Lek Listy 107: 366-373, 2006.

38. Tian XQ, Zhang L, Yang L, Huang P, Qian X, Huang PL and Zhang LD: A possible anti-apoptosis mechanism of hyperbaric oxygen in rats with memory impairments induced by A $\beta 25-35$ Chin J Phys Med Rehabil 36: 7-11, 2014.

39. van Praag H, Kempermann G and Gage FH: Neural consequences of environmental enrichment. Nat Rev Neurosci 1: 191-198, 2000.

40. Brown J, Cooper-Kuhn CM, Kempermann G, Van Praag H, Winkler J, Gage FH and Kuhn HG: Enriched environment and physical activity stimulate hippocampal but not olfactory bulb neurogenesis. Eur J Neurosci 17: 2042-2046, 2003.

41. Kobilo T, Liu QR, Gandhi K, Mughal M, Shaham Y and van Praag H: Running is the neurogenic and neurotrophic stimulus in environmental enrichment. Learn Mem 18: 605-609, 2011.

42. Herring A, Ambree O, Tomm M, Habermann H, Sachser N, Paulus W and Keyvani K: Environmental enrichment enhances cellular plasticity in transgenic mice with Alzheimer-like pathology. Exp Neurol 216: 184-192, 2009.

43. Ji XY, Zhang LN, Liu R, Liu YZ, Song JF, Dong H, Jia YF and Zhou ZG: Potential targets for protecting against hippocampal cell apoptosis after transient cerebral ischemia-reperfusion injury in aged rats. Neural Regen Res 9: 1122-1128, 2014.

44. Hitti FL and Siegelbaum SA: The hippocampal CA2 region is essential for social memory. Nature 508: 88-92, 2014.

45. Han WN, Yuan L, Liu XJ, Zhou LW, Wu MN and Qi JS: The correlation study between spatial memory and hippocampal long term potentiation in rats. Chin J Behav Med Brain Sci 21 630-633, 2012

46. Zhao CH, Su P, Lv C, Guo LM, Cao GQ, Qin CX and Zhang WS: Berberine alleviates amyloid $\beta$-induced mitochondrial dysfunction and synaptic loss. Oxid Med Cell Longev 2019: 7593608, 2019.

47. Serrano-Pozo A, Frosch MP, Masliah E and Hyman BT: Neuropathological alterations in Alzheimer disease. Cold Spring Harb Perspect Med 1: a006189, 2011.

48. Tu S, Okamoto S, Lipton SA and Xu H: Oligomeric A $\beta$-induced synaptic dysfunction in Alzheimer's disease. Mol Neurodegener 9: 48, 2014.

49. Raven F, Van der Zee EA, Meerlo P and Havekes R: The role of sleep in regulating structural plasticity and synaptic strength: Implications for memory and cognitive function. Sleep Med Rev 39: 3-11, 2018.

50. Holtmaat A and Svoboda K: Experience-dependent structural synaptic plasticity in the mammalian brain. Nat Rev Neurosci 10 647-658, 2009.

51. Rochefort NL and Konnerth A: Dendritic spines: From structure to in vivo function. EMBO Rep 13: 699-708, 2012

52. Mavroudis IA, Fotiou DF, Manani MG, Njaou SN, Frangou D, Costa VG and Baloyannis SJ: Dendritic pathology and spinal loss in the visual cortex in Alzheimer's disease: A Golgi study in pathology. Int J Neurosci 121: 347-354, 2011.

53. Song JM, DiBattista AM, Sung YM, Ahn JM, Turner RS, Yang J, Pak DT, Lee HK and Hoe HS: A tetra(ethylene glycol) derivative of benzothiazole aniline ameliorates dendritic spine density and cognitive function in a mouse model of Alzheimer's disease. Exp Neurol 252: 105-113, 2014

54. Bae J, Sung BH, Cho IH, Kim SM and Song WK: NESH regulates dendritic spine morphology and synapse formation. PLoS One 7: e34677, 2012.

55. Petrinovic MM, Hourez R, Aloy EM, Dewarrat G, Gall D, Weinmann O, Gaudias J, Bachmann LC, Schiffmann SN Vogt KE and Schwab ME: Neuronal Nogo-A negatively regulates dendritic morphology and synaptic transmission in the cerebellum. Proc Natl Acad Sci USA 110: 1083-1088, 2013
56. Hu XL, Bergström SA, Brink M, Rönnbäck A and Dahlqvist P Enriched environment increases spinophilin mRNA expression and spinophilin immunoreactive dendritic spines in hippocampus and cortex. Neurosci Lett 476: 79-83, 2010.

57. Liu N, He S and Yu X: Early natural stimulation throughenvironmental enrichment accelerates neuronal development inthe mouse dentate gyrus. PLoS One 7: e30803, 2012.

58. De Bartolo P, Florenzano F, Burello L, Gelfo F and Petrosini L: Activity-dependent structural plasticity of purkinje cell spines in cerebellar vermis and hemisphere. Brain Struct Funct 220: 2895-2904, 2015.

59. Liu ZT, Yu TH, Qu TB, Li L and Chu LS: Effect of buyanghuanwu decoction on the expression of growth-associated protein 43 and synaptophysin after focal cerebral ischemia in mice. Chin J Behav Med Brain Sci 21: 1070-1072, 2012

60. Kwon SE and Chapman ER: Synaptophysin regulates the kinetics of synaptic vesicle endocytosis in central neurons. Neuron 70 847-854, 2011

61. Huo DS, Sun JF, Zhang BF, Yan XS, Wang H, Jia JX and Yang ZJ: Protective effects of testosterone on cognitive dysfunction in Alzheimer's disease model rats induced by oligomeric beta amyloid peptide 1-42. J Toxicol Environ Health A 79: 856-863, 2016.

62. Jia JX, Yan XS, Cai ZP, Song W, Huo DS, Zhang BF, Wang H and Yang ZJ: The effects of phenylethanoid glycosides, derived from herba cistanche, on cognitive deficits and antioxidant activities in male SAMP8 mice. J Toxicol Environ Health A 80: 1180-1186, 2017.

63. Zhou CL, Zhao L, Shi HY, Liu JW, Shi JW, Kan BH, Li Z, Yu JC and Han JX: Combined acupuncture and HuangDiSan treatment affects behavior and synaptophysin levels in the hippocampus of senescence-accelerated mouse prone 8 after neural stem cell transplantation. Neural Regen Res 13: 541-548, 2018.

64. Dong WG, Yang WD, Li FF, Guo WQ, Qian CH, Wang F, Li CZ, Lin L and Lin RH: Electroacupuncture improves synaptic function in SAMP8 mice probably via inhibition of the AMPK/eEF2K/eEF2 signaling pathway. Evid Based Complement Alternat Med 2019: 8260815, 2019.

65. Hussain M, Berger M, Eckenhoff RG and Seitz DP: General anesthetic and the risk of dementia in elderly patients: Current insights. Clin Interv Aging 9: 1619-1628, 2014.

66. Lazarov O, Robinson J, Tang YP, Hairston IS, Korade-Mirnics Z, Lee VM, Hersh LB, Sapolsky RM, Mirnics K and Sisodia SS: Environmental enrichment reduces $A \beta$ levels and amyloid deposition in transgenic mice. Cell 120: 701-713, 2005.

67. Ambree O, Leimer U, Herring A, Görtz N, Sachser N, Heneka MT, Paulus W and Keyvani K: Reduction of amyloid angiopathy and $\mathrm{A} \beta$ plaque burden after enriched housing in TgCRND8 mice. Am J Pathol 169: 544-552, 2006.

68. Berardi N, Braschi C, Capsoni S, Cattaneo A and Maffei L: Environmental enrichment delays the onset of memory deficits and reduces neuropathological hallmarks in a mouse model of Alzheimer-like neurodegeneration. J Alzheimers Dis 11: 359-70, 2007.

69. Ziegler-Waldkirch S, Marksteiner K, Stoll J, d'Errico P, Friesen M, Eiler D, Neudel L, Sturn V, Opper I, Datta M, et al: Environmental enrichment reverses $A \beta$ pathology during pregnancy in a mouse model of Alzheimer's disease. Acta Neuropathol Commun 6: 44, 2018.

70. Phillips C, Baktir MA, Das D, Lin B and Salehi A: The link between physical activity and cognitive dysfunction in Alzheimer disease. Phys Ther 95: 1046-1060, 2015.

71. Dong JD, Zhou M, Wu XQ, Du MY and Wang XS: Memantine combined with environmental enrichment improves spatial memory and alleviates Alzheimer's disease-like pathology in senescence-accelerated prone-8 (SAMP8) mice. J Biomed Res 26: 439-447, 2012

72. Tian Q, Jia J, Qu XH, Chen Y, GuoYL and Zhang MZ: Effect of neuregulin on expressions of apoptosis and nuclear factor kappa B in hippocampus of Alzheimer's disease model rats. Chin J Behav Med Brain Sci 21: 26-29, 2012.

73. Izzo NJ, Xu JB, Zeng CB, Kirk MJ, Mozzoni K, Silky C, Rehak C, Yurko R, Look G, Rishton G, et al: Alzheimer's therapeutics targeting amyloid beta1-42 oligomers II: Sigma-2/PGRMC1 receptors mediate Abeta 42 oligomer binding and synaptotoxicity. PLoS One 9: e111899, 2014.

74. Squitti R: Copper subtype of Alzheimer's disease (AD) Meta-analyses, genetic studies and predictive value of non-ceruloplasmin copper in mild cognitive impairment conversion to full AD. J Trace Elem Med Biol 28: 482-485, 2014. 
75. Zhang HJ, Zhao CH, Lv C, Liu XL, Du SJ, Li Z, Wang YY and Zhang WS: Geniposide alleviates amyloid-induced synaptic injury by protecting axonal mitochondrial trafficking. Front Cell Neurosci 10: 309, 2017.

76. Asih PR, Tegg ML, Sohrabi H, Carruthers M, Gandy SE, Saad F, Verdile G, Ittner LM and Martins RN: Martins RN multiple mechanisms linking type 2 diabetes and Alzheimer's disease: Testosterone as a modifer. J Alzheimers Dis 59: 445-466, 2017.

77. Song L, Li XP, Bai XX, Gao J and Wang CY: Calycosin improves cognitive function in a transgenic mouse model of Alzheimer's disease by activating the protein kinase $\mathrm{C}$ pathway. Neural Regen Res 12: 1870-1876, 2017.

78. Wang XN, Hu XJ, Yang Y, Takata T and Sakurai T: Nicotinamide mononucleotide protects against $\beta$-amyloid oligomer-inducedc ognitive impairment and neuronal death. Brain Res 1643: 1-9, 2016.

79. Yan XS, Yang ZJ, Jia JX, Song W, Fang X, Cai ZP, Huo DS and Wang H: Protective mechanism of testosterone on cognitive impairment in a rat model of Alzheimer's disease. Neural Regen Res 14: 649-657, 2019.

80. Stairs DJ and Bardo MT: Neurobehavioral effects of environmental enrichment and drug abuse vulnerability. Pharmacol Biochem Behav 92: 377-382, 2009.

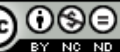

This work is licensed under a Creative Commons Attribution-NonCommercial-NoDerivatives 4.0 International (CC BY-NC-ND 4.0) License. 